\title{
A comparative study of conventional vs. laparoscopic operations in the surgical management of peritonitis
}

\author{
Carmen-Loredana Gorgan', Florian Popa', Liviu Draghici'1,2 \\ 1"Carol Davila" University of Medicine and Pharmacy, Bucharest, Romania \\ ${ }^{2}$ Department of General Surgery, "Sf. Ioan" Emergency Clinical Hospital, Bucharest, Romania
}

\begin{abstract}
Purpose and objectives. The purpose of this paper was to compare the "outcomes" of patients with peritonitis according to the surgical method selected (laparoscopic vs. conventional/open), in the treatment of such a severe pathology, in order to obtain an efficient management of postoperative morbidities and the reduction of the mortality rate (currently estimated at $5 \%-40 \%$ ).

Material and method. We carried out a retrospective, observational, non-randomized study on a sample of hospitalized patients, based on a descriptive and analytical epidemiological investigation, supported by the laparoscopic experience of the General Surgery Clinic in "Sf. Ioan" Emergency Clinical Hospital of Bucharest in the last decade (01.01.2009-31.12.2018).

Results. We identified a sample of 378 patients with peritonitis, of which 109 were operated laparoscopically (i.e. $28.84 \%$ ), and 269 patients (i.e. $71.16 \%$ ) were operated traditionally. Following a rough analysis, it was observed that patients who underwent open surgery were hospitalized on an average 4.73 days longer than those operated laparoscopically (11.67 days vs. 6.94 days), the effect being statistically significant $(p<0.01)$. In the traditionally operated group of patients, the average duration of surgery was 46.31 minutes longer than those operated laparoscopically (113.92 vs. 67.60$)$, the effect being also statistically significant $(p<0.01)$. Conclusions. The conventional surgical approach is statistically significantly associated with an increased duration of operative time and hospitalization in patients with peritonitis and can be considered a factor of severe evolutive prognosis in the therapeutic management of this pathology.
\end{abstract}

Keywords: peritonitis, laparotomy, prognostic factors, sepsis

\section{INTRODUCTION}

The diagnosis of peritonitis is obtained based on preoperative imaging investigations (ultrasonography, computed tomography) or by diagnostic laparoscopy, with the evidence of purulent fluid in the peritoneal cavity. As not all surgeons have a high level of training in laparoscopic surgery, it is recommended that in patients with acute abdomen be treated laparoscopically or by open surgery, taking into account the presence of a well-trained surgical team, and not by randomly assigning a certain type of approach [1].

The prognosis of peritonitis through organ perforations is still unfavourable, despite state-of-theart diagnostic and treatment techniques. Therefore, early diagnosis of patients with severe peritonitis is very important in selecting cases for emergency surgery [2-6].

Numerous studies [7-13] have demonstrated the usefulness of the minimally invasive method in the management of abdominal emergencies due to peritonitis. The feasibility, safety and advantages of minimally invasive surgery compared to conventional techniques are emphasized, the open surgical procedures being also taken into account.

On the other hand, a deliberate conversion of a laparoscopic operation to the classical technique should not be seen as a reduced preference of the surgeon for the laparoscopic approach of the patient with peritonitis, but rather appreciated as a 
surgical maturity in choosing the type of operation (conventional/laparoscopic), for the severe cases.

Not to be neglected are the undeniable advantages of the classical intervention, such as: the possibility of performing an eventual laborious viscerolysis caused by severe inflammatory reshaping, the rigorous lavage of the peritoneal cavity, and the excision of various digestive segments compromised by the pathological process, interventions whose magnitude would often make it practically impossible to apply the laparoscopic technique in solving these cases. On the other hand, we cannot overlook the fact that patients complain of intense pain in the first days post-surgery, mobilize and breathe with difficulty, slowly resume their digestive tolerance and intestinal transit, being exposed to the risk of pulmonary complications [14-15].

The identification of certain evolutive prognostic factors in the conventional vs laparoscopic approach of peritonitis is a continuous concern of specialists, which would crown the desire to obtain an effective management of morbidities and to reduce mortality.

\section{MATERIAL AND METHOD}

This article presents the results of a retrospective, observational, non-randomized study on a sample of hospitalized patients, based on a descriptive and analytical epidemiological investigation, supported by the laparoscopic experience of the General Surgery Clinic in "Sf. Ioan" Emergency Clinical Hospital of Bucharest in the last decade (01.01.2009-31.12.2018).

Three sources of statistical data were used: the existing statistical data in the hospital archive and the Hippocrates record program, the clinical observation sheets of patients and the surgical protocols that provided data on the nature of surgery (laparoscopic/conventional), the duration of surgery, the severity of peritonitis and intraperitoneal lesions, the appearance of peritoneal exudate at the time of intervention, the solving method through a laparoscopic/conventional intervention. In our study, all conversions were considered open operations, taking into account only the cases in which surgery was performed ( $\mathrm{N}=378$ cases), and excluding the patients who benefited exclusively from conservative therapy.

Single and multiple univariate linear regression models (if necessary), bidirectional Welch T-type tests for two independent samples were used in inferential statistics, for continuous variables. For the category variables and the identification of evolutive prognostic factors with testing the power of the association between possible factors and their effect, techniques specific to the analytical epidemiological investigations were used, namely, simple and multiple linear regression (if necessary), calculating odd ratio (OR), coefficients and confidence intervals $[\mathrm{CI}] 95 \%$. The $\chi^{2}$ (chi-square) test was used to compare categorical data for two or more independent proportions; the test was considered to have statistical significance at a sensitivity level $1-\alpha=0.95$ (the statistical significance threshold was of $\mathrm{p} £ 0.05$ ).

We compared the "outcomes" of patients with peritonitis according to the therapeutic modality (laparoscopic vs conventional/open). When there were important differences between the two groups, a direct comparison of the "outcomes" between the two groups could have been inconclusive because of the differences between the variables that influence the "outcome" (the "confounding" phenomenon). To avoid this effect, we resorted to a solution such as "attenuating" the differences between the two groups using a propensity score, based on age, gender and the origin of peritonitis, a score that will be used in comparison tests.

There are two ways of building the propensity score. In this study, we have chosen the "ATE" (average treatment effect) methodology offered by the "twang" package in R which uses as methodology an increased generalized regression - "boost" (offered by the "gbm" package in R).

For comparison, the "survey" package in R was used, which allows comparison tests with penalties. To calculate the propensity score (arguments for the $\mathrm{p}_{\mathrm{s}}$ function in the twang package) we used the following parameters: $n$.trees (number of iterations of the argument) $=5000$, interaction.depth $=3$ (interaction level allowed in gbm, value recommended by the authors of the twang package), shrinkage $=0.001$ (algorithm accuracy), perm.test. iters $=500$ (number of Monte Carlo trials to determine $\mathrm{p}$ values for the Kolmogorov-Smirnov statistics); we mention that the determination of the parameter values (except interaction.depth) was an iterative process, the optimal values being determined with the help of diagnostic charts, and was obviously limited by the computational power we had at our disposal.

\section{RESULTS}

The comparative analysis of the prognostic factors such as age, gender, origin of peritonitis and duration of surgery was performed for 378 cases of 
peritonitis (109 laparoscopic surgeries vs. 269 conventional surgeries) from which complete data was obtained.

A careful analysis of the groups according to the type of surgery (laparoscopic/conventional) shows that almost $30 \%$ of the peritonitis cases were laparoscopically operated (see table 1).

TABLE 1. Analysis of the group of patients with peritonitis according to the type of surgery (laparoscopic/conventional)

\begin{tabular}{|c|c|}
\hline Surgery type & Patient lot (N = 378) \\
\hline Laparoscopic - No (\%) & $109(28.84)$ \\
\hline Open - No (\%) & $269(71.16)$ \\
\hline
\end{tabular}

The distribution of cases according to the type of surgery (conventionalvs. laparoscopic) for the peritonitis cases is shown in figure 1. The analysis indicates a greater propensity of the surgical teams to the classical surgical treatment, probably also due to the severity of lesions, often diagnosed by exploratory laparoscopy, as a primary operative time.

Table 2 compares the prognostic factors for the two groups (laparoscopic vs. conventional). In the table we notice that there were important differences between the two groups, therefore, to avoid the "confounding" phenomenon, we resorted to "attenuating" the differences between the two groups by using a propensity score, based on age, gender and origin of peritonitis, a score to be used in the comparison tests.

Below are the diagnostic charts (for the final model), which will help us compare the degree of risk for the two groups (see figures 2-3).

The chart shows that the distributions of the propensity scores have approximately identical minimum and maximum values.

A difference attenuation of the 3 initial parameters is observed, in two of the parameters the differences becoming without statistical significance (full circles are the differences that have statistical significance, empty circles are the differences without statistical significance, unweighted represents the situation before the propensity score penalty, weighted represents the situation after the propensity score penalty).

In table 3 and figure 4 we analyzed the relative influence of the 3 variables (age, gender, origin of
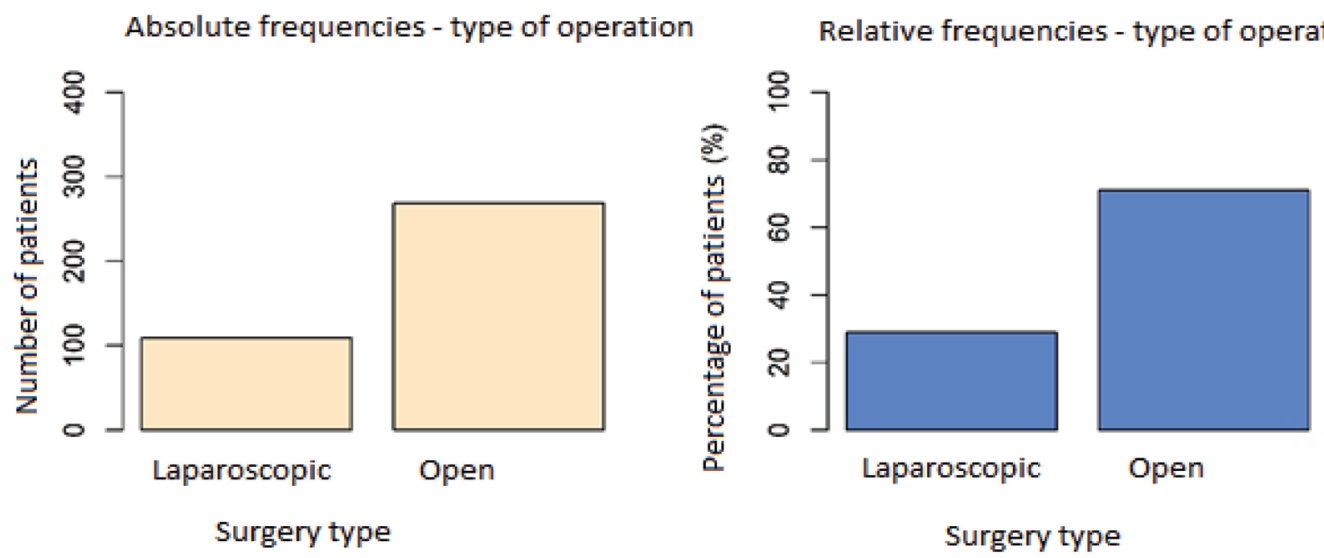

FIGURE 1. Distribution of peritonitis cases according to the type of surgery (conventional vs. laparoscopic) - bar plots of absolute and relative frequencies

TABLE 2. Analysis of evolutive prognostic factors for the peritonitis cases operated laparoscopically vs. open

\begin{tabular}{|l|c|c|c|}
\hline Parameter & Laparoscopy & Conventional & Differences p value \\
\hline Age - Average + S.D. & $42.53 \pm 15.70$ & $50.38 \pm 15.90$ & $<0.0001^{1}$ \\
\hline Gender M -\% & 40.37 & 54.65 & $<0.0001^{2}$ \\
\hline Origin of appendicitis (\%) & 35.78 & 8.18 & $<0.0001^{3}$ \\
Genital (\%) & 27.52 & 12.64 & - \\
Gall bladder (\%) & 9.17 & 3.72 & - \\
Other origins (\%) & 25.69 & 20.07 & - \\
Gastric (\%) & 1.83 & 29.37 & \\
Colon Rectum (\%) & 0.00 & 14.87 & \\
Small intestine (\%) & 0.00 & 11.15 & \\
\hline${ }^{1}$ Welch T Test & ${ }^{2} \chi^{2}$ test & ${ }^{3} \mathrm{G}$ test & \\
\hline
\end{tabular}




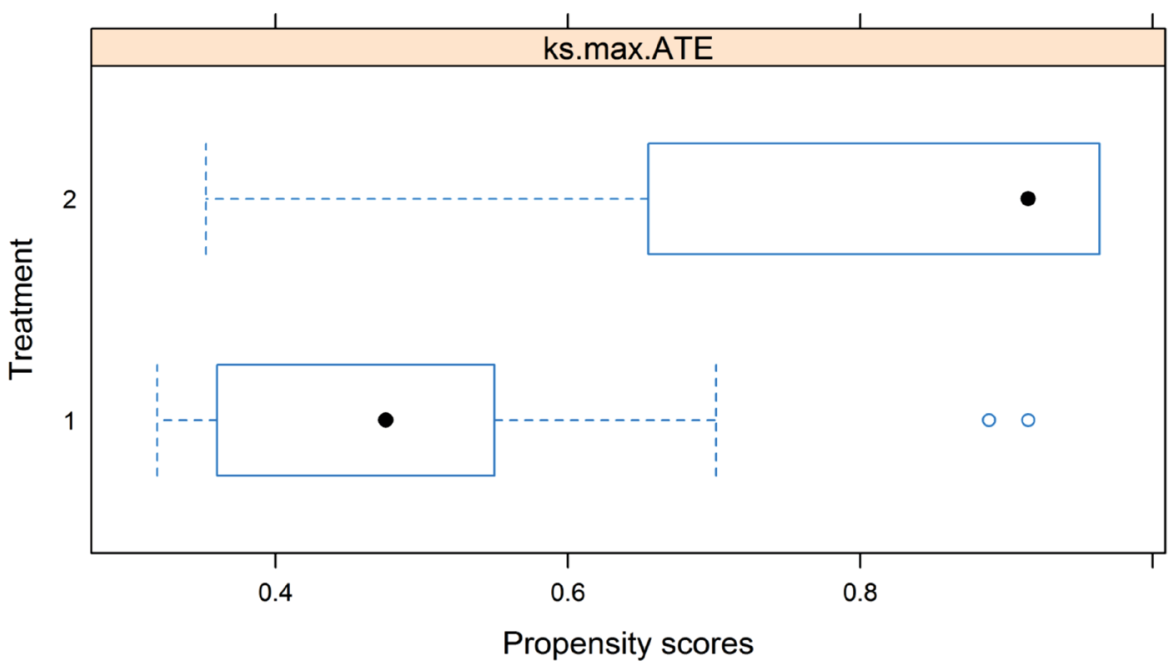

FIGURE 2. Diagnostic chart comparing the propensity scores

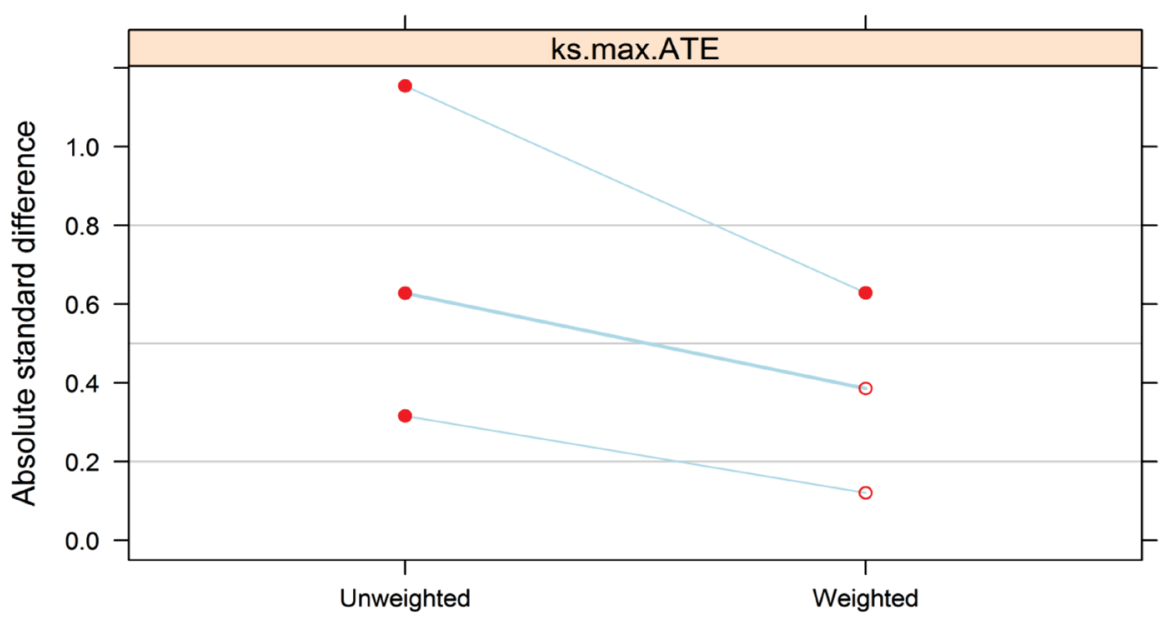

FIGURE 3. Diagnostic chart comparing differences before attenuation to those after attenuation

peritonitis) in the conventional and laparoscopic groups, for patients with peritonitis.

TABLE 3. Relative influence depending on variables

\begin{tabular}{|c|c|}
\hline Variable & Relative influence \\
\hline Origin of peritonitis & 76.71 \\
\hline Age & 22.74 \\
\hline
\end{tabular}

Next, an analysis was made of the influence of the type of operation on the 2 "endpoints" of interest (hospitalization duration, operation duration), first the rough analysis (without any penalty) and then adjusted, and to increase the accuracy, we decided to use a "double robust" method, taking as a model both the propensity score and the variables that can influence the outcome (age, gender, origin of peritonitis).

For continuous variables (duration of operation, duration of hospitalization), a simple univariate lin- ear regression model was used for the simple analysis, with the dependent variable the "outcome" to be analysed, and the independent variable the type of operation (laparoscopic or classical) - see table 4, while for the penalized analysis (using the propensity score), a multiple univariate linear regression was used, with the same dependent variable and with independent variables the type of operation, age, gender and origin of peritonitis - see table 5 .

TABLE 4. Rough analysis of hospitalization duration(comparisons are conventional vs. laparoscopic)

\begin{tabular}{|l|c|c|c|}
\hline Variable & $\begin{array}{c}\text { T } \\
\text { statistic }\end{array}$ & $\begin{array}{c}\mathbf{P} \\
\text { value }\end{array}$ & $\begin{array}{c}\text { Coefficient } \\
\text { [Cl 95\%] }\end{array}$ \\
\hline $\begin{array}{l}\text { Open vs. } \\
\text { laparoscopic surgery }\end{array}$ & 3.43 & 0.0007 & $4.73[2.03$ to 7.44$]$ \\
\hline
\end{tabular}




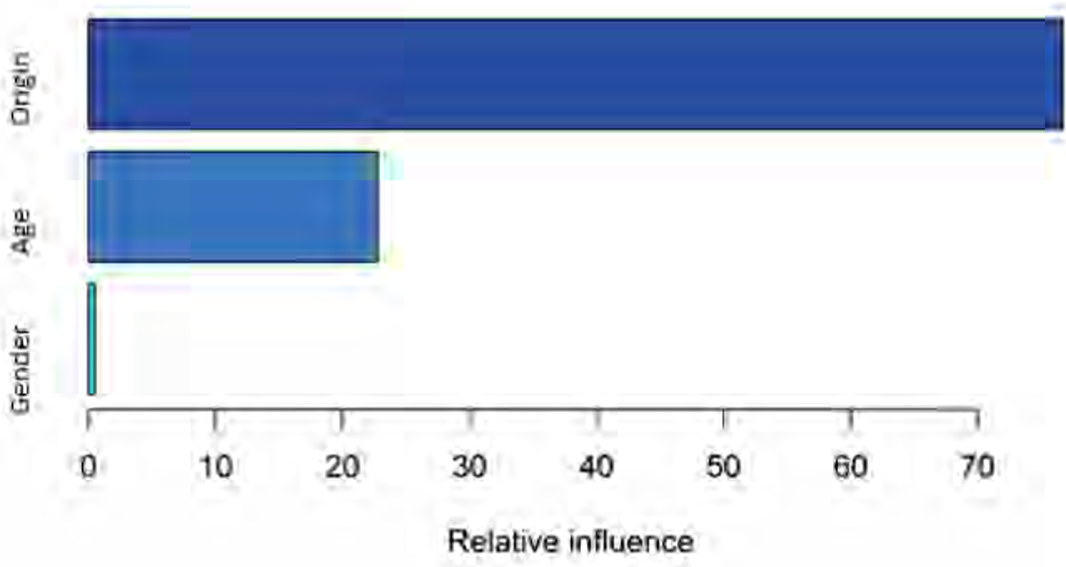

FIGURE 4. Relative influence depending on variables

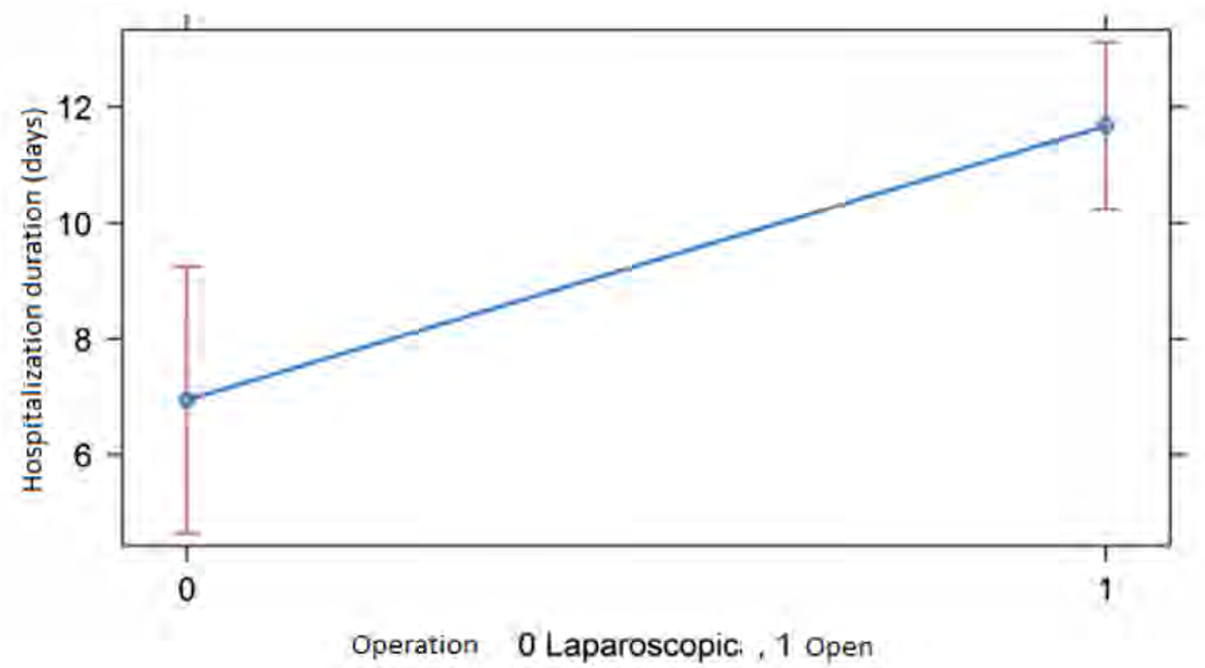

FIGURE 5. Influence of the type of operation (conventional/laparoscopic) on the hospitalization duration - rough analysis

Patients who underwent open surgery were hospitalized on average 4.73 days longer than those operated laparoscopically (11.67 days vs. 6.94 days), the effect being statistically significant $(\mathrm{p}<0.01)$, as can be seen in figure 5 .

TABLE 5. Penalized analysis for the duration of hospitalization in patients with peritonitis

\begin{tabular}{|l|c|c|c|}
\hline Variable & $\begin{array}{c}\mathbf{T} \\
\text { statistic }\end{array}$ & $\begin{array}{c}\mathbf{P} \\
\text { value }\end{array}$ & $\begin{array}{c}\text { Coefficient } \\
\text { [Cl 95\%] }\end{array}$ \\
\hline $\begin{array}{l}\text { Open (vs. } \\
\text { laparoscopic) surgery }\end{array}$ & 1.80 & 0.0017 & $2.81[1.07$ to 4.85] \\
\hline
\end{tabular}

In the analysis that considers other variables, patients who underwent classical surgery remained hospitalized only 2.81 days longer than those laparoscopically operated (a decrease of 2 days compared to the rough analysis), the effect remaining statistically significant $(\mathrm{p}<0.01)-$ see also figure 6 .
In table 6 we performed the rough analysis for the continuous variable - operation duration, using a simple univariate linear regression model.

TABLE 6. Rough analysis for the duration of the operation

\begin{tabular}{|l|c|c|c|}
\hline Variable & $\begin{array}{c}\text { T } \\
\text { statistic }\end{array}$ & $\begin{array}{c}\mathbf{P} \\
\text { value }\end{array}$ & $\begin{array}{c}\text { Coefficient } \\
{[\mathbf{C l} \text { 95\%] }}\end{array}$ \\
\hline $\begin{array}{l}\text { Open (vs. } \\
\text { laparoscopic) surgery }\end{array}$ & 17.36 & $<0.0001$ & $\begin{array}{c}46.31 \\
{[37.31 \text { to 55.32] }}\end{array}$ \\
\hline
\end{tabular}

In the group of classically operated patients, the average duration of the operation was $46.31 \mathrm{~min}$ utes longer than those laparoscopically operated (113.92 vs 67.60), the effect being statistically significant $(\mathrm{p}<0.01)$ - see figure 7 .

This statistically significant difference in the duration of operations (classical and laparoscopic) for peritonitis is natural, if we take into account the additional tens of minutes allocated to the onset times 


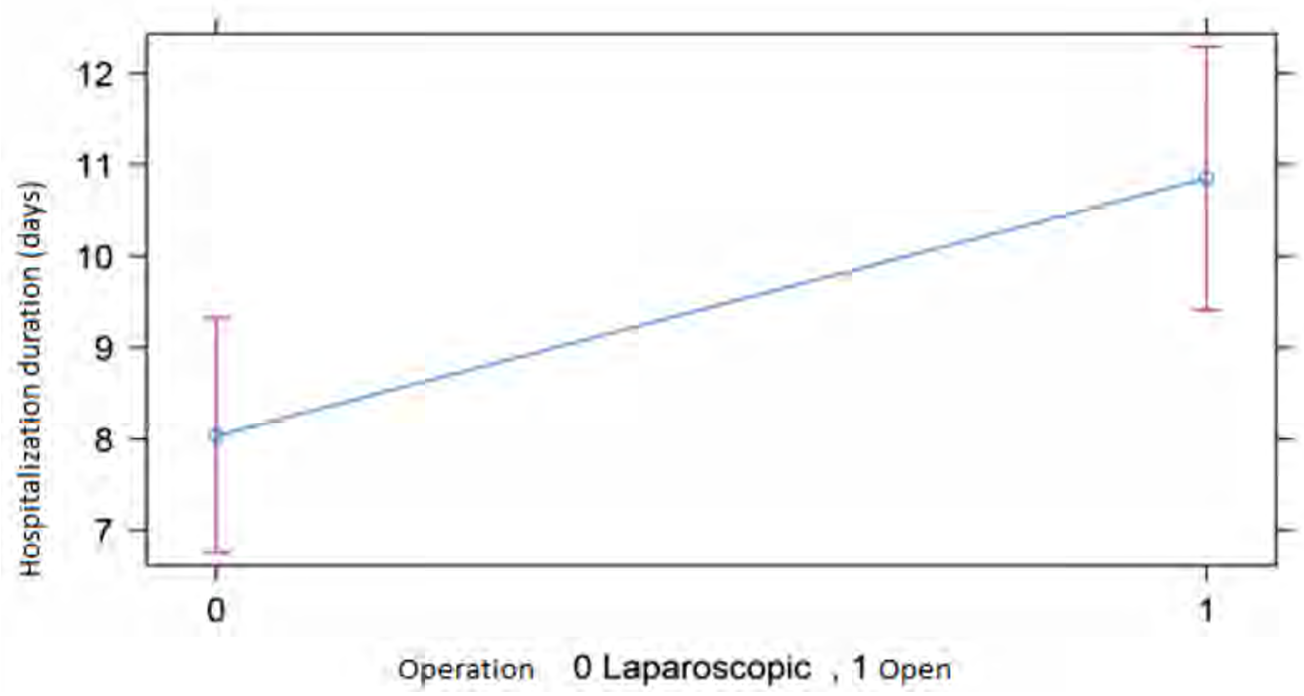

FIGURE 6. The influence of the surgery type (conventional/laparoscopic) on the hospitalization duration -penalized analysis

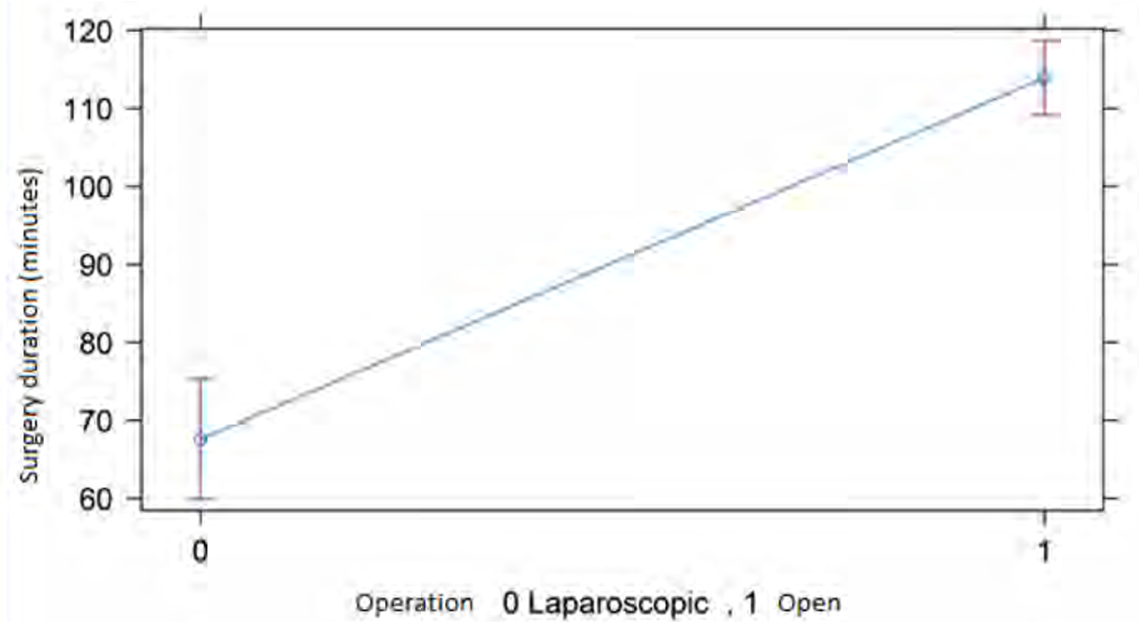

FIGURE 7. Influence of the surgery type (conventional/laparoscopic) on the duration of the operation - rough analysis

(access to the peritoneal cavity) and the end times (closure of the wide laparotomy), in the classical interventions, incomparably more than the few minutes allocated to these operating times during the laparoscopic procedure.

In table 7 we performed the penalized analysis for the continuous variable - the duration of the operation, using a simple univariate linear regression model.

TABLE 7. Penalized analysis for the duration of the operation

\begin{tabular}{|l|c|c|c|}
\hline Variable & $\begin{array}{c}\mathbf{T} \\
\text { statistic }\end{array}$ & $\begin{array}{c}\mathbf{P} \\
\text { value }\end{array}$ & $\begin{array}{c}\text { Coefficient } \\
\text { [Cl 95\%] }\end{array}$ \\
\hline $\begin{array}{l}\text { Open (vs. laparoscopic) } \\
\text { surgery }\end{array}$ & 6.07 & $<0.0001$ & $\begin{array}{c}28.28[19.15 \\
\text { to 37.42] }\end{array}$ \\
\hline
\end{tabular}

Compared to the rough analysis, following the penalized analysis, the difference decreased to
28.28 minutes, the effect still having statistical significance $(\mathrm{p}<0.01)$ - see also figure 8 .

Therefore, based on the rough analysis, patients who underwent open surgery were hospitalized on average 4.73 days longer than those laparoscopically operated (11.67 days vs. 6.94 days), the effect being statistically significant $(\mathrm{p}<0.01)$; in the penalized analysis, which also takes into account the other variables, patients who underwent conventional surgery remained hospitalized only 2.81 days longer than those laparoscopically operated (a decrease of 2 days compared to the rough analysis), the effect remaining statistically significant $(\mathrm{p}<0.01)$.

Also, in the group of classically operated patients, the average duration of surgery was 46.31 minutes longer than those operated laparoscopically (113.92 vs. 67.60), the effect being statistically 


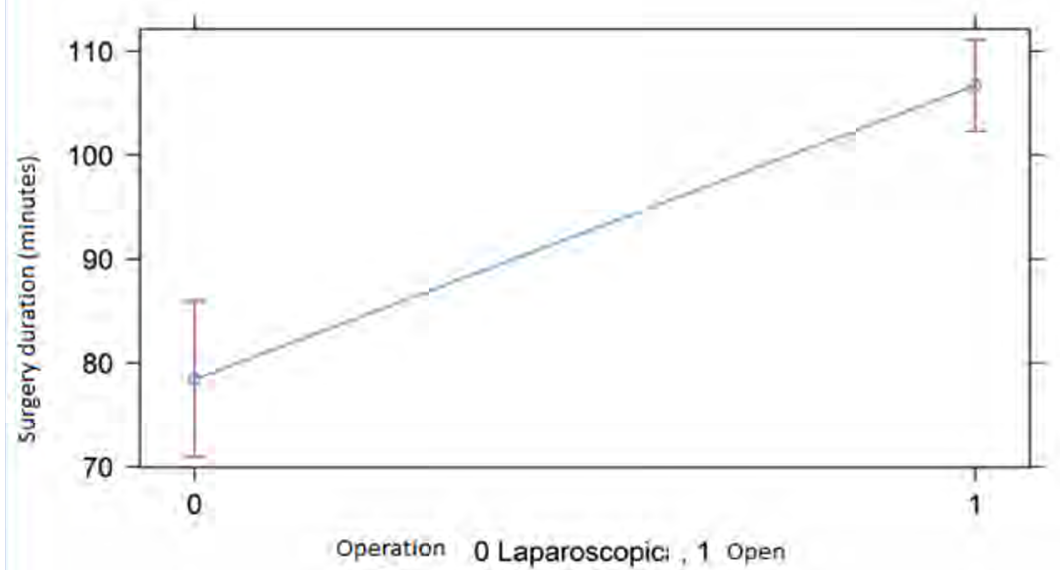

FIGURE 8. Influence of the surgery type (conventional/laparoscopic) on the duration of the operation - penalized analysis

significant $(\mathrm{p}<0.01)$, and following the penalized analysis, the difference decreased to 28.28 minutes, the effect continuing to have statistical significance $(\mathrm{p}<0.01)$.

\section{DISCUSSION}

The comparative study between the groups of patients with peritonitis, traditionally vs. laparoscopically operated, has been the concern of specialists for a long time. In an analysis [13] of 138 cases ( $85 \mathrm{men} / 53$ women) with a mean age of 46.5 years who underwent laparoscopic surgery, peritonitis was present in $92(66.6 \%)$ cases. The exact cause of peritonitis was established in $88 \%$ (81 of 92) by laparoscopy. Conversion to laparotomy was required in 17 patients to clarify the diagnosis suspected by laparoscopy. Thus, upon laparoscopic examination, the preoperative clinical diagnosis was changed in $31(22.4 \%)$ cases, thus avoiding an unnecessary laparotomy in $10(7.2 \%)$ of these patients.

In our practice, depending on the severity of the case, we opted for either surgery (conventional/laparoscopic) in immediate emergency or in planned emergency (delayed), in order to rebalance the patient's hemodynamics and improve their biological status.

Other authors prefer to perform planned laparotomies 48 hours after admission. However, there is no evidence of the definite benefits of planned surgery in the specialty literature [16-18].

Regarding the surgeon's options for solving cases through a certain type of surgical approach depending on the origin of peritonitis, we can say that, in principle, in the General Surgery Clinic of "St. Ioan" Hospital of Bucharest, the diagnosis of peritonitis of any kind, has not been a contraindication for laparoscopic operations.

In a retrospective study [19] in South America, performed on a group of 227 patients with appendicular peritonitis, $43 \%$ of them were men with an average age of $39 \pm 17$ (range: $12-85$ years old). 97 cases (43\%) underwent laparoscopic appendicectomy, with a conversion rate of $13 \%$ (13 cases). According to the authors, there were no differences in the approach rate of diffuse peritonitis in the two groups (laparoscopic and conventional), which was found in 48 of 130 patients in the group with classical appendectomy (36.9\%), compared to 46 of 97 patients in the laparoscopic group $(47.4 \%, p=0.13)$. According to the same South American authors [19], laparoscopic appendectomy had a longer operating period, but a shorter hospital stay $(\mathrm{p}<0.05)$, while open appendectomy had a shorter operating time $(\mathrm{p}<0.001)$, but a longer hospital stay $(\mathrm{p}=0.02)$, compared to laparoscopic surgery.

Several Mexican surgeons [20] at the "Hospital Español de Mèxico" have published the results of a study conducted in 2005-2009 on a group of 73 patients ( 31 men and 42 women) operated for the diagnosis of acute surgical abdomen with peritonitis, whose average age was 58.4 (28-83 years old). In these patients, peritonitis was caused by: appendicitis in 52 cases, diverticulitis in 13 patients and perforated ulcers in 8 of them. They reported an average duration of laparoscopic surgery for cases of peritonitis of 148 minutes (60-220 min) and an average duration of hospitalization of 6 days.

Regarding another etiology of peritonitis, it is well known that the issue of choosing laparoscopic cholecystectomy versus classical cholecystectomy, in the approach of acute cholecystitis complicated by biliary peritonitis, has been intensively analysed 
in the last 3 decades. The laparoscopic technique is now unanimously accepted as feasible for the surgical treatment of acute cholecystitis, and early laparoscopic cholecystectomy is safer and has lower complication rates compared to delayed surgery [21]. Thus, several studies [22-25] have shown that early laparoscopic surgery led to a significantly shorter hospital stay compared to delayed laparoscopic cholecystectomy, with no significant differences in the rate of complications and conversions.

Surprisingly, a study by Biondi et al. [26] on 593 appendectomies (310 operated classically and 283 operated laparoscopically) obtained short hospitalization duration for the classical group compared to the length of hospital stay for the laparoscopic group $(2.7 \pm 2.5$ days for the laparoscopic group and $1.4 \pm 0.6$ days for the group of classical operations), corresponding to a significantly shorter operating time in the open group $(31.36 \pm 11.13$ min open and $54.9 \pm 14.2$ laparoscopic). This result was correlated with other previous results [27-29]. In contrast, some studies have not shown significant differences in terms of hospital stay between the two groups, classical and laparoscopic [30,31].

However, data from the literature mention, in the case of appendectomies for appendicular perforations [32], a duration of hospitalization in the open group (8.9 days), significantly longer than in the laparoscopic group (4.1 days, $\mathrm{p}<0.05$ ).

In an Irish comparative study [33] on approach techniques in peritonitis by perforated sigmoid diverticulitis ( $3^{\text {rd }}$ and $4^{\text {th }}$ degree Hinchey), there was a significant reduction in the operative time in laparoscopic peritoneal lavage, as opposed to laparoscopic sigmoid resection $(\mathrm{WMD}=-72.105,95 \%$ $\mathrm{CI}=-88.335$ to $-55.876, \mathrm{p}<0.0001)$, emphasizing that, among specialists [34-38], there are still heated debates over the appropriate therapeutic strategy for this type of pathology. However, there seems to be a general consensus that laparoscopic peritoneal lavage should not be used for patients with $4^{\text {th }}$ degree Hinchey perforated sigmoid diverticulitis [33-35,39-46].

The well-known advantages of laparoscopic surgery with regards to the the short duration of hospitalization and rapid socio-professional reintegration are also highlighted by a systematic review of literature data on peritonitis by perforated ulcer [47-49]. Thus, a study [50] comparing 843 patients in the laparoscopic group and 1,031 patients in the open surgery group showed a reduction in the length of hospital stay from 10.3 days to 6.3 days in favour of the laparoscopic group compared to open surgery patients. Other authors [47] reported a mean decrease of 2.9 days, which had a statistically significant reduction in favour of laparoscopic surgery for the surgical treatment of perforated ulcers.

\section{CONCLUSIONS}

The surgical treatment by classical approach of patients with peritonitis is statistically significantly associated with increased duration of surgery and hospitalization. The open surgical technique is a severe evolutive prognostic factor in the surgical treatment of these patients.

\section{Acknowledgement}

All the authors are main authors, with equal scientific contributions in the preparation of the article.

Conflict of interest: none declared Financial support: none declared

\section{REFERENCES}

1. Agresta F, Ciardo L.F, Mazzarolo G, Michelet I, Orsi G, Trentin G, Bedin N. Peritonitis: laparoscopic approach. World Journal of Emergency Surgery 2006;1:9.

2. Arasu VT, Lakshmipathy N. A Prospective study of evaluation of Mannheim Peritonitis Index to predict outcome of patients with peritonitis. International Journal of Contemporary Medical Research 2016;11(3):3339-41.

3. Wacha H, Linder MM, Feldman U, Wesch G, Gundlach E, Steifensand RA. Mannheim peritonitis index - prediction of risk of death from peritonitis: Construction of a statistical and validation of an empirically based index. Theoretical Surg. 1987;1:169-77.

4. Correia MM, Thuler LCS, Velasco E, Vidal EM, Schanaider A. Peritonitis Index in oncologic patients. Revista Brasileira de Cancerologia. 2001;47:63-68.

5. Billing A, Frohlich D, Schildberg FW. Prediction of outcome using the Mannheim peritonitis index in 2003 patients. Peritonitis Study Group. Br J Surg. 1994;81:209-13.

6. Agrawal CS, Niranjan M, Adhikary S, Karki BS, Pandey R, Chalise PR. Quality assurance in the management of peritonitis: A prospective study. Nepal Med Coll J. 2009;11:83-87.

7. Sinha R, Sharma N, Joshi M. Laparoscopic repair of small bowel perforation. JSLS. 2005;9:399-402.

8. Robertson GS, Wemyss-Holden SA, Maddern GJ. Laparoscopic repair of perforated peptic ulcers. The role of laparoscopy in generalised peritonitis. Ann R Coll Surg Engl. 2000;82:6-10.

9. Navez B, Tassetti V, Scohy JJ, Mutter D, Guiot P, Evrard S. Marescaux J. Laparoscopic management of acute peritonitis. $\mathrm{Br} \mathrm{J}$ Surg. 1998;85:32-36.

10. Kirshtein B, Roy-Shapira A, Lantsberg L, Mandel S, Avinoach E, Mizrahi S. The use of laparoscopy in abdominal emergencies. Surg Endosc. 2003;17(7):1118-1124.

11. Nagy AG, James D. Diagnostic laparoscopy. Am J Surg. 1989; 157(5):490-3. 
12. Navez B, d'Udekem Y, Cambier E, Richir C, de Pierpont B, Guiot P. Laparoscopy for management of nontraumatic acute abdomen. World J Surg. 1995;19:382-386; discussion 387.

13. Sangrasi AK, Talpur KAH, Kella N, Laghari AA, Abbasi MR, Qureshi JN. Role of laparoscopy in peritonitis. Pak J Med Sci. 2013; 4(29):1028-1032.

14. Draghici I, Draghici L. General considerations in laparoscopic method. In: Fundamental principles in pediatric laparoscopic surgery, Draghici I (ed.), Addleton Academic Publishers, New York 2014.

15. Journal of Indian Association of Pediatric Surgeons, 2010 OctoberDecember, pages 122-126 available at http://www.jiaps.com.

16. Lamme B, Boermeester MA, Reitsma JB, Mahler CW, Obertop H et al. Meta-analysis of relaparotomy for secondary peritonitis. Br J Surg. 2002;89:1516-24.

17. Reinhart K, Brunkhorst FM, Bone HG, Bardutzky J, Dempfle CE et al. Prevention, diagnosis, treatment, and follow-up care of sepsis. First revision of the S2k Guidelines of the German SepsisSociety (DSG) and the German Interdisciplinary Association for Intensive and Emergency Care Medicine (DIVI). Ger Med Sci. 2010;59:347-370.

18. Kujath P, Eckmann C, Esnaashari H, Bruch HP. The value of different lavage treatment patterns in diffuse peritonitis. Zentralb/ Chir. 2007; 132:427-432.

19. Quezada F, Quezada N, Mejia R, Brañes A, Padilla O, Jarufe N et al. Laparoscopic versus open approach in the management of appendicitis complicated exclusively with peritonitis: A single center experience. Int J Surg. 2015;13:80-83.

20. Alvarez JF, Pichardo O, Baqueiro A, Gòmez JM, Terrazas F, Leòn I, Vargas $\mathrm{G}$. Laparoscopic management of generalized peritonitis. Available at https://www.sages.org/meetings/annual-meeting/ abstracts-archive/laparoscopic-management-of-generalizedperitonitis.

21. Sartelli M. A focus on intra-abdominal infections. World Journal of Emergency Surgery 2010;5:9.

22. Lau H, Lo CY, Patil NG, Yuen WK. Early versus delayed-interval laparoscopic cholecystectomy for acute cholecystitis. A meta-analysis. Surg Endosc. 2006;20(1):82-87.

23. Papi C, Catarci M, D’Ambrosio L, Gili L, Koch M, Grassi GB, Capurso L. Timing of cholecystectomy for acute cholecystitis: A meta-analysis. Am J Gastroenterol. 2004;99(1):147-155.

24. Gurusamy KS, Samraj K. Early versus delayed laparoscopic cholecystectomy for acute cholecystitis. Cochrane Database Syst Rev. 2006;18(4):CD005440.

25. Shikata S, Noguchi Y, Fukui T. Early versus delayed cholecystectomy for acute cholecystitis: A meta-analysis of randomized controlled trials. Surg Today. 2005;35(7):553-560.

26. Biondi A, di Stefano C, Ferrara F, Bellia A, Vacante M, Piazza L. Laparoscopic vs. open appendectomy: A retrospective cohort study assessing outcomes and cost-effectiveness. World J Emerg Surg. 2016;11:44.

27. Sauerland S, Jaschinski T, Neugebauer EA. Laparoscopic vs. open surgery for suspected appendicitis. Cochrane Database Syst Rev. 2010;(10):CD001546.

28. Guller U, Hervey S, Purves H, Muhlbaier LH, Peterson ED, Eubanks $S$ et al. Laparoscopic versus open appendectomy: Outcomes comparison based on a large administrative database. Ann Surg. 2004;239:43-52.

29. Li X, Zhang J, Sang L, Zhang W, Chu Z, Li X, Liu Y. Laparoscopic vs conventional appendectomy - a meta-analysis of randomized controlled trials. BMC Gastroenterol. 2010;10:129.

30. Katkhouda N, Mason RJ, Towfigh S, Gevorgyan A, Essani R. Laparoscopic vs open appendectomy: A prospective randomized double-blind study. Ann Surg. 2005;242:439-448; discussion 448-50.

31. Chung RS, Rowland DY, Li P, Diaz J. A meta-analysis of randomized controlled trials of laparoscopic vs. conventional appendectomy. Am J Surg. 1999;177:250-6.
32. Schietroma M, Piccione F, Carlei F, Clementi M, Bianchi Z, De Vita F. Amicucci G. Peritonitis from perforated appendicitis: Stress response after laparoscopic or open treatment. The American Surgeon 2012; 5(78):582-590.

33. Shaikh FM, Stewart PM, Walsh SR, Davies RJ. Laparoscopic peritoneal lavage or surgical resection for acute perforated sigmoid diverticulitis: A systematic review and meta-analysis. International Journal of Surgery 2017;(38):130-37.

34. O'Sullivan GC, Murphy D, O'Brien MG, Ireland A. Laparoscopic management of generalized peritonitis due to perforated colonic diverticula. Am J Surg. 1996;171(4):432-4.

35. Myers E, Hurley M, O'Sullivan G.C, Kavanagh D, Wilson I, Winter DC. Laparoscopic peritoneal lavage for generalized peritonitis due to perforated diverticulitis. Br J Surg. 2008;95(1):97-101.

36. Sauerland S, Agresta F, Bergamaschi R, Borzellino G, Budzynski A, Champault $G$, Fingerhut $A$, Isla $A$, Johansson $M$, Lundorff $P$, Navez $B$, Saad S, Neugebauer EA. Laparoscopy for abdominal emergencies: Evidence-based guidelines of the European association for endoscopic surgery. Surg Endosc. 2006;20(1):14-29.

37. Santaniello M, Bergamaschi R. Perforated diverticulitis: Should the method of surgical access to the abdomen determine treatment? Colorectal Dis. 2007;9(6):494-5.

38. Rogers AC, Collins D, O'Sullivan GC, Winter DC. Laparoscopic lavage for perforateddiverticulitis: A population analysis. Dis Colon Rectum. 2012;55(9):932-8.

39. Bretagnol F, Pautrat K, Mor C et al. Emergency laparoscopic man7agement of perforated sigmoid diverticulitis: A promising alternative to more radical procedures. J Am Coll Surg. 2008; 206:654-7.

40. Faranda C, Barrat C, Catheline JM, Champault GG. Twostage laparoscopic management of generalized peritonitis due to perforated sigmoid diverticula: Eighteen cases. Surg Laparosc Endosc Percutan Tech. 2000;10:135-8.

41. Da Rold AR, Guerriero S, Fiamingo P et al. Laparoscopic colorrhaphy, irrigation and drainage in the treatment of complicated acute diverticulitis: Initial experience. Chir Ital. 2004;56:95-8.

42. Taylor CJ, Layani L, Ghusn MA, White SI. Perforated diverticulitis managed by laparoscopic lavage. ANZ J Surg. 2006;76:962-5.

43. Mutter D, Bouras G, Forgione A et al. Two-stage totally minimally invasive approach for acute complicated diverticulitis. Colorectal Dis. 2006;8:501-5.

44. Vennix S, Musters GD, Mulder IM, et al. Ladies trial colloborators. Laparoscopic peritoneal lavage or sigmoidectomy for perforated diverticulitis with purulent peritonitis: A multicentre, parallel-group, randomised, open-label trial. Lancet 2015;386:1269-77.

45. Thornell A, Angenete E, Bisgaard T et al. Laparoscopic Lavage for Perforated Diverticulitis With Purulent Peritonitis: A Randomized Trial. Ann Intern Med. 2016;164:137-45.

46. Schultz JK, Yaqub S, Wallon C et al. SCANDIV Study Group. Laparoscopic Lavage vs Primary Resection for Acute Perforated Diverticulitis: The SCANDIV Randomized Clinical Trial. JAMA 2015; 314:1364-75.

47. Siow SL, Mahendran HA, Wong CM, Hardin M, Luk TL. Laparoscopic versus open repair of perforated peptic ulcer: Improving outcomes utilizing a standardized technique. Asian J Surg. 2018;41(2):136-42.

48. Katkhouda N, Mavor E, Mason RJ, Campos GM, Soroushyari A, Berne TV. Laparoscopic repair of perforated duodenal ulcers: Outcome and efficacy in 30 consecutive patients. Arch Surg. 1999; 134:845-850.

49. Bertleff MJ, Halm JA, Bemelman WA et al. Randomized clinical trial of laparoscopic versus open repair of the perforated peptic ulcer: The LAMA Trial. World J Surg. 2009;33(7):1368-73.

50. Bertleff M.J, Lange JF. Laparoscopic correction of perforated peptic ulcer: First choice? A review of literature. Surg Endosc. 2010; 24:1231-39. 